\title{
Atmospheric Pressure Plasma Jet Treatment of PCL Polymer Solutions to Improve Electrospinning
}

Silvia Grande ${ }^{*}$, Joachim Van Guyse ${ }^{2}$, Anton Y. Nikiforov ${ }^{1}$, Iuliia Onyshchenko ${ }^{1}$, Mahtab Asadian $^{l}$, Rino Morent ${ }^{l}$, Richard Hoogenboom ${ }^{2}$ and Nathalie De Geyter ${ }^{1}$

${ }^{1}$ Research Unit Plasma Technology (RUPT), Department of Applied Physics, Faculty of Engineering and Architecture, Ghent University, Sint-Pietersnieuwstraat 41 B4, 9000 Ghent, Belgium

${ }^{2}$ Department of Organic and Macromolecular Chemistry, Supramolecular Chemistry Group, Faculty of Sciences, Ghent University, Krijgslaan 281 S4, 9000 Ghent, Belgium

KEYWORDS. Electrospinning, APPJ, plasma-liquid interactions, Argon plasma, polymer solution, surface morphology, nanofibers

ABSTRACT. An atmospheric pressure plasma jet (APPJ) specifically designed for liquid treatment has been used in this work to improve the electrospinnability of a $5 \mathrm{w} / \mathrm{v} \%$ solution of poly- $\varepsilon$-caprolactone (PCL) in a mixture of chloroform and $N, N$-dimethylformamide. Untreated PCL solutions were found to result in non-uniform fibers containing a large number of beads, 
while plasma-treated solutions (exposure time of 2 to 5 minutes) enabled the generation of beadless, uniform nanofibers with an average diameter of $450 \mathrm{~nm}$. This enhanced electrospinnability was found to be mainly due to the highly-increased conductivity of the plasmamodified PCL solutions. Consequently, more stretching of the polymer jet occurred during electrospinning leading to the generation of bead-free fibers. Plasma treatment also results in an increased viscosity and decreased $\mathrm{pH}$ values. To explain these observed changes, optical emission spectroscopy (OES) has been used to examine the excited species present in the APPJ in contact with the PCL solution. This study revealed peaks attributed to $\mathrm{H}, \mathrm{CH}, \mathrm{CH}_{2}$ and $\mathrm{C}_{2}$ species which could be responsible of the degradation of solvent molecules and/or PCL structure during the plasma treatment. Size exclusion chromatography (SEC) and X-ray photoelectron spectroscopy (XPS) results showed that the molecular weight and the chemical composition of PCL were not significantly affected by the APPJ treatment. Plasma exposure mainly results in degradation of the solvent molecules instead of modifying the PCL macromolecules, preserving as much as possible the original polymer. A hypothesis for the observed macroscopic changes in viscosity and $\mathrm{pH}$ could be the generation of new chemical species such as for example $\mathrm{HCl}$ and/or $\mathrm{HNO}_{3}$. These species are characterized by high conductivity, low $\mathrm{pH}$ value, strong polarity and could enhance the solvent quality for PCL leading to expansion of the polymer coil, which could in turn explain the observed enhanced viscosity after plasma modification.

\section{INTRODUCTION}

Electrospinning is a unique and efficient fabrication process capable of producing fibrous polymer mats with fiber diameters ranging from several microns down to values below $100 \mathrm{~nm}^{1}$. With smaller pores and higher surface area than regular fibers, electrospun fibrous mats have been 
successfully applied in various fields such as catalysis ${ }^{2}$, sensors ${ }^{3-4}$, biomedicine ${ }^{5}$, filtration ${ }^{6}$ and electronics ${ }^{7-8}$. In a typical electrospinning process, a high voltage is used to create an electrically charged jet of a polymer solution, which dries on extrusion due to solvent evaporation to leave a polymer fiber ${ }^{9}$. Various process and ambient parameters, such as the applied electrical field, tip to collector distance, solution flow rate, and humidity can be manipulated to obtain the desired fiber morphology ${ }^{10}$. However, one of the greatest challenges in electrospinning is the preparation of a polymer solution suitable for electrospinning. Indeed, in order to create continuous bead-free fibers, the polymer solution should fulfill many requirements in terms of rheological behavior, conductivity and surface tension ${ }^{11}$. A commonly used strategy to improve the electrospinnability of polymer solutions is to increase the solution conductivity by increasing the polarity of the solvent using solvent mixtures or by the addition of salts ${ }^{12-15}$. However, this approach often involves additional costs, safety concerns as well as environmental issues. Within this context, it is thus important to search for effective, environmentally friendly, non-toxic methods to improve the electrospinnability of polymer solutions ${ }^{16}$. Recently, it has been shown that an atmospheric pressure plasma can be a viable method to increase the electrospinnability of a polymer solution 17-18. Atmospheric pressure plasmas have been widely used to modify the surface of polymer materials including electrospun nanofibers because of their numerous advantages over traditional chemical modification processes ${ }^{19-20}$. However, research on the use of atmospheric pressure plasmas for polymer solution treatment is rarely performed. Until now, only two research papers dealing with plasma modification of pre-electrospinning polymer solutions have been published. In 2011, Shi et al. manipulated the electrospinnability of an aqueous polyethylene oxide (PEO) solution by exposing it to an atmospheric pressure dielectric barrier discharge (DBD) ${ }^{18}$. Results showed that plasma treatment significantly improved fiber morphology resulting in finer, smoother 
nanofibers possessing a low amount of beads. Very recently, Colombo et al. investigated the effect of an atmospheric pressure plasma jet on the electrospinnability of a poly(L-lactic acid) (PLLA) solution in dichloromethane ${ }^{17}$. The applied plasma treatment enabled the production of defectfree PLLA fibers from a $100 \%$ dichloromethane solution. Despite the great potential of atmospheric pressure plasma treatment of pre-electrospinning polymer solutions, research has been very limited so far. This article aims to expand research on this topic by investigating the

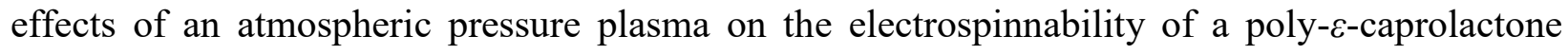
(PCL) solution in a mixture of chloroform $\left(\mathrm{CHCl}_{3}\right)$ and $N, N$-dimethylformamide (DMF). PCL is used as polymer since it is one of the most commonly researched materials in tissue engineering ${ }^{21}$. Electrospinning of PCL has already been successfully performed in several solvents including acetone, mixtures of acetic acid and formic acid and mixtures of chloroform and DMF with PCL concentrations varying between 10 to $40 \mathrm{w} / \mathrm{v}^{2}{ }^{22-24}$. This work however intends to successfully electrospin a polymer solution containing a very low PCL concentration ( $5 \mathrm{w} / \mathrm{v} \%)$ by making use of a plasma pre-treatment of the polymer solution.

An argon atmospheric pressure plasma jet will be used as plasma source in this work: the applied experimental set-up is specifically designed for the treatment of liquid polymer solutions enabling a close and intense contact between the plasma and the polymer solution, which is expected to result in a strong improvement of the quality of the resultant nanofibers. In a first part of the article, the atmospheric pressure plasma jet will be electrically characterized and the excited plasma species generated in the discharge will be determined. Next, PCL polymer solutions will be treated with the plasma jet and the plasma-modified solutions will be extensively characterized in terms of viscosity, conductivity, $\mathrm{pH}$ and polymer molecular weight. Finally, the untreated and plasma- 
modified PCL polymer solutions will be electrospun to investigate the effect of plasma treatment on the final morphology and the chemical composition of the generated PCL nanofibers.

\section{EXPERIMENTAL METHODS}

\subsection{Materials}

PCL pellets with a number average molecular mass $M_{n}=80000 \mathrm{~g} / \mathrm{mol}$ were purchased from Sigma-Aldrich and used without further purification. $\mathrm{CHCl}_{3}$ and $\mathrm{DMF}$ with a purity $>99 \%, N, N-$ dimethylacetamide (DMA) and $\mathrm{LiCl}$ were also purchased from Sigma-Aldrich and used as such. Argon gas (Alphagaz 1) was purchased from Air Liquide.

\subsection{Preparation of PCL polymer solutions}

PCL pre-electrospinning polymer solutions are prepared by dissolving PCL pellets in a solvent mixture $(9: 1 \mathrm{v} / \mathrm{v})$ composed of $\mathrm{CHCl}_{3}$ and $\mathrm{DMF}$ at a concentration of $5 \% \mathrm{w} / \mathrm{v}$. Afterwards, the polymer solution is mechanically stirred for 3 hours at room temperature. Control samples are kept at room temperature and are electrospun without any plasma treatment, while other samples are exposed to a plasma modification step after which samples are electrospun.

\subsection{Atmospheric pressure plasma jet treatment}

The plasma source used in this work to treat PCL polymer solutions is an atmospheric pressure plasma jet (APPJ), specifically designed for liquid treatment and schematically represented in Figure 1 (A). The plasma is generated inside a thin, quartz capillary with an inside and outside diameter of 1.3 and $3.0 \mathrm{~mm}$ respectively. As high-voltage electrode, a tungsten wire with a 
diameter of $1 \mathrm{~mm}$ and a half-sphere-shaped tip inside the quartz capillary is used. A ring-shaped electrode with a length of $10 \mathrm{~mm}$ placed at a distance of $45 \mathrm{~mm}$ from the high-voltage electrode and $20 \mathrm{~mm}$ away from the edge of the capillary acts as grounded electrode. High purity argon is used to generate the plasma and flows at a rate of $0.90 \mathrm{slm}$ (standard litres per minute) through the capillary. The discharge itself is generated by applying an $\mathrm{AC}$ voltage (fixed frequency of 50 $\mathrm{kHz}$ ) to the high-voltage electrode with a peak-to-peak value of $7.6 \mathrm{kV}$. At an applied peak-topeak voltage of less than $6 \mathrm{kV}$, only a weak radiation zone is observed inside the capillary on the tip of the high-voltage electrode, which is a well-known corona discharge. However, an increase in applied voltage results in the formation of a bright plasma in the inter-electrode gap with a long out flowing plasma propagating outside the capillary (so-called plasma afterglow). A small reactor chamber, which can contain the polymer solution, is made by fixing a quartz tube with an inside and outside diameter of $13 \mathrm{~mm}$ and $20 \mathrm{~mm}$ respectively to a stainless-steel flange with a small opening on the bottom side where the APPJ quartz capillary can be inserted, as shown in Figure 1. Prior to plasma modification, the argon gas rate is switched on to prevent the polymer solution flowing inside the plasma capillary and successively the reactor chamber is filled with $10 \mathrm{ml}$ of the polymer solution using a plastic syringe, ensuring a close and intense contact between the plasma afterglow and the PCL solution. The reactor chamber is covered at the top with a stainless-steel flange containing a small opening as gas outlet to limit solvent evaporation during treatment. Plasma treatments in this work are conducted at a fixed discharge power for different treatment times.

The most common electrical diagnostic of an APPJ consists of the measurement of the voltage applied to the wire electrode and the resultant charge on the electrodes. The voltage applied to the wire electrode is measured using a high voltage probe (Tektronix P6015A), whereas the charge on 
the electrodes is obtained by measuring the voltage over a capacitor of $10 \mathrm{nF}$ in series with the plasma jet. By visualizing the obtained voltage-versus-charge plot using a PC oscilloscope (Picoscope 3204A), a Lissajous figure can be constructed ${ }^{25}$. From this figure, the electrical energy consumed per voltage cycle $\mathrm{E}_{\mathrm{el}}$ can be estimated since this value is equal to the area enclosed by the Lissajous figure. The electrical power $\mathrm{P}_{\mathrm{el}}$ can be obtained by multiplying the electrical energy with the frequency of the feeding voltage, which is $50 \mathrm{kHz}$ in this work ${ }^{25}$, and was found to be equal to $4.8 \mathrm{~W}$.
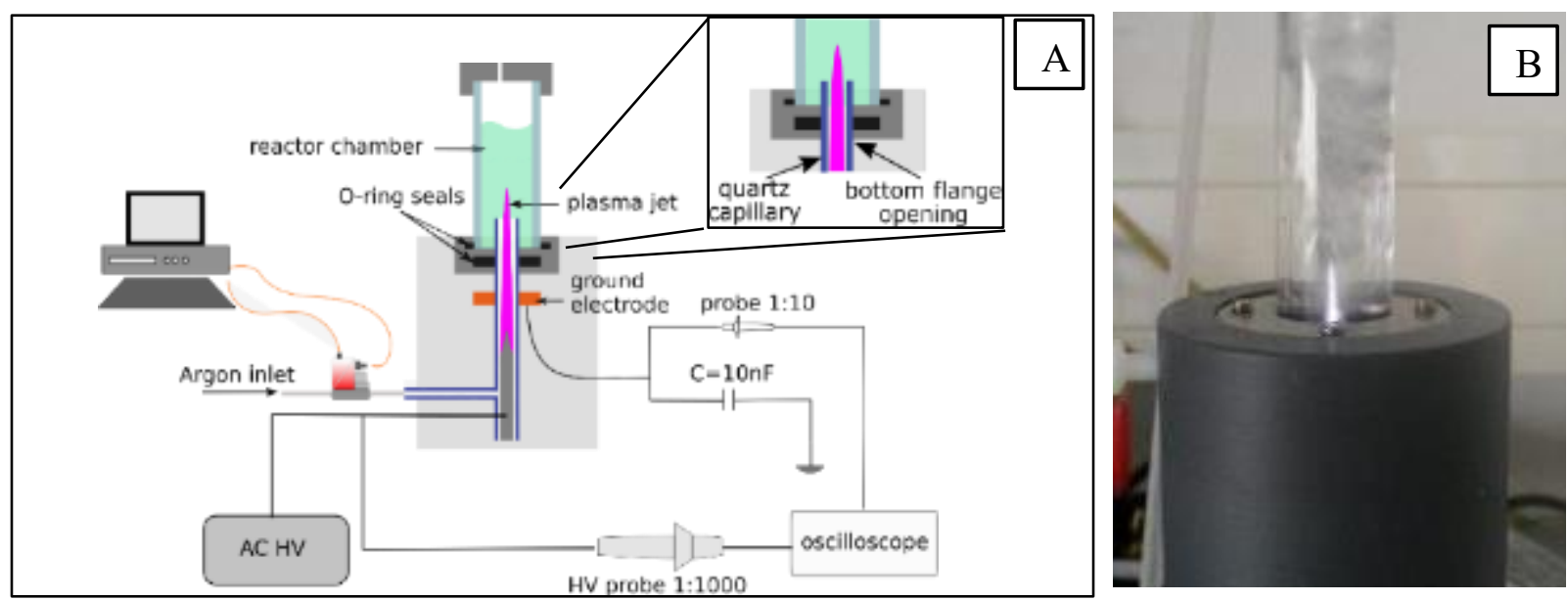

Figure 1. (A) Schematic representation of the atmospheric pressure plasma jet used to modify PCL polymer solutions. The zoomed area represents the cross-section of the flange at the bottom of the reactor chamber where the APPJ quartz capillary is inserted. The seals which prevent the liquid leakage are O-ring shaped and represented in black; (B) a photograph of the working plasma jet in contact with a PCL polymer solution.

To identify the excited plasma species generated in the discharge, optical emission spectra of the plasma jet are also recorded by means of an Ocean Optic S2000 spectrometer in the range $200-$ $900 \mathrm{~nm}$ with a low resolution of $0.7 \mathrm{~nm}$. These spectra are obtained $13 \mathrm{~mm}$ from the edge of the capillary: this allows us to determine which plasma species are generated in close contact with the polymer solution. 


\subsection{Electrospinning}

The bottom-up electrospinning process in this work is conducted using a customized Nanospinner 24 electrospinning machine (Inovenso) at room temperature, schematically presented in Figure 2. Untreated and plasma-treated PCL solutions are collected in a $5 \mathrm{ml}$ glass syringe and for the plasma-treated solutions, collection is performed immediately after plasma treatment. The syringe is subsequently placed in a syringe pump (NE-300 Just Infusion ${ }^{\mathrm{TM}}$ syringe pump) which controls the flow rate of the polymer solution through a polyethylene tube (inner diameter of 2 $\mathrm{mm}$ ) ending in an aluminum feeding pipe containing a single brass nozzle with an inner diameter of $0.8 \mathrm{~mm}$. During the electrospinning process, the polymer flow rate is maintained at $5 \mathrm{ml} / \mathrm{h}$. The metallic nozzle is vertically placed below a stainless-steel rotating $(100 \mathrm{rpm})$ collector at a distance of $20.0 \mathrm{~cm}$. During the electrospinning process, a voltage of $25 \mathrm{kV}$ is supplied to the nozzle, while the cylinder is grounded. In this work, nanofibers are directly collected on an aluminum foil taped to the collecting cylinder. This metallic substrate is selected because (1) it can be easily rolled around the rotating collector and (2) it can be easily removed from the cylinder after conducting the electrospinning process. Nanofiber characterization is then subsequently performed without peeling off the nanofibers from the aluminum foil to avoid any damage to the nanofiber morphology. 


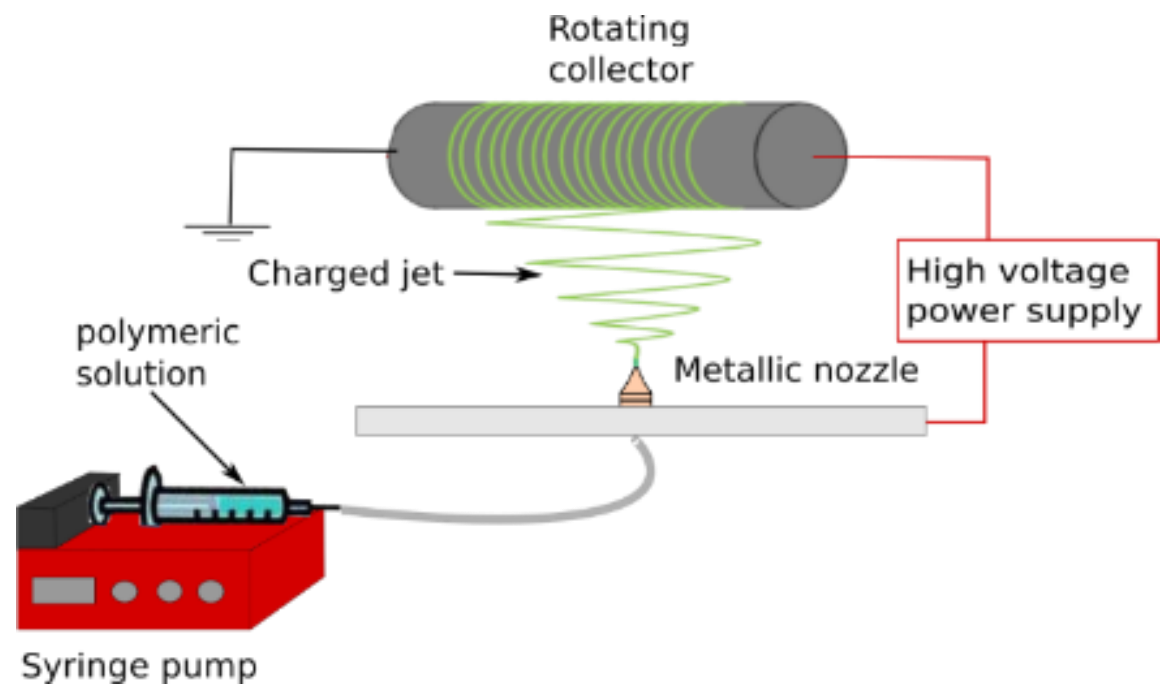

Figure 2. Schematic representation of the electrospinning equipment used to electrospin control and plasma-modified PCL polymer solutions.

\subsection{Chemical and physical characterization of the PCL polymer solutions}

To physically characterize the PCL polymer solution, several important solution parameters which can influence the electrospinning process are measured before and after plasma treatment: (1) conductivity, (2) viscosity, (3) surface tension, and (4) pH. Solution conductivity is determined using a FiveEasy ${ }^{\mathrm{TM}}$ conductivity meter (Mettler Toledo) equipped with an InLab720 conductivity probe operating in a conductivity range of 0.1 to $500 \mu \mathrm{S} / \mathrm{cm}$, while the $\mathrm{pH}$ of the solution is obtained making use of a FiveEasy ${ }^{\mathrm{TM}} \mathrm{pH}$ meter equipped with an InLab Science Pro-ISM $\mathrm{pH}$ probe specifically designed to relatively estimate $\mathrm{pH}$ values in organic solvents. Solution viscosity is obtained using a DV2T EXTRA viscometer (Brookfield Engineering Laboratories). To determine the surface tension of the PCL solutions, a K20 EasyDyne Instrument (Krüss GmbH) is used based on the Wilhelmy plate method ${ }^{26}$. The volume of the polymeric solution before and after plasma treatment is also measured to evaluate possible changes in polymer concentration in the solution due to solvent evaporation. 
To examine whether the plasma modification is not degrading the PCL polymer chains, sizeexclusion chromatography (SEC) experiments are performed in this work as it is an excellent chromatographic technique to reveal information on the molecular weight (MW) distribution of a polymer ${ }^{27}$. In this work, SEC measurements are conducted on an Agilent 1260-series system equipped with a 1260 online degasser, a 1260 ISO-pump, a 1260 automatic liquid sampler, a column compartment at a constant temperature of $50^{\circ} \mathrm{C}$ equipped with two PLgel $5 \mu \mathrm{m}$ mixed-D columns and a pre-column in series, a 1260 diode array detector and a 1260 refractive index detector. DMA containing $50 \mathrm{mM}$ of $\mathrm{LiCl}$ at a flow rate of $0.500 \mathrm{ml} / \mathrm{min}$ is used as eluent. The 50 $\mathrm{mM} \mathrm{LiCl}$ in DMA solution is filtered before use, making use of a filter with a pore size of $0.2 \mu \mathrm{m}$. The obtained spectra are visualized and analysed using Agilent Chemstation software in combination with Agilent gel permeation chromatography data analysis software.

\subsection{Chemical and physical characterization of PCL nanofibers}

The surface morphology of the obtained nanofibers is imaged using a JEOL JSM-6010 PLUS/LV scanning electron microscope (SEM). The SEM images are acquired with an accelerating voltage of 7 and $14 \mathrm{kV}$, after coating the samples with a thin layer of gold making use of a sputter coater (JFC-1300 autofine coater, JEOL). The average diameter of the nanofibers is determined through the measurement of 40 different fibers making use of ImageJ analysis software. Visualization of the polymer electrospinning jet during the electrospinning process has also been performed making use of a Nikon D 3200 camera equipped with a Tamron AF 70-300 $\mathrm{mm}$ lens and operated at an exposure time of $0.1 \mathrm{~s}$.

Besides morphology, also the surface chemical composition of the generated nanofibers is examined to investigate whether the plasma modification step is affecting it or not. For this purpose, XPS spectra are recorded with a PHI 5000 Versaprobe II spectrometer employing a 
monochromatic $\mathrm{Al} \mathrm{K} \mathrm{K}_{\alpha} \mathrm{X}$-ray source $(\mathrm{h} v=1486.6 \mathrm{eV}$ ) operating at a power of $43.5 \mathrm{~W}$ (beam size of $50 \mu \mathrm{m})$. In a first step, survey scans, measuring 2 samples with 5 points per sample are recorded with a pass energy of $187.85 \mathrm{eV}$ at a take-off angle of $45^{\circ}$ relative to the sample surface to identify the elements present on the PCL nanofibers. Element quantification, based on these survey scans, is subsequently performed using Multipak software (V 9.6) with a Shirley background by applying the relative sensitivity factors supplied by the manufacturer of the instrument. In a next step, high resolution $\mathrm{C} 1 \mathrm{~s}$ and $\mathrm{O} 1 \mathrm{~s}$ peaks are also recorded with a pass energy of $23.5 \mathrm{eV}$ to gain knowledge on the different chemical groups present on the surface of the nanofibers. Multipak software is again used to curve fit these peaks after the energy scale is calibrated with respect to the hydrocarbon component of the $\mathrm{C} 1 \mathrm{~s}$ spectrum $(285.0 \mathrm{eV})$. Afterwards, Gaussian-Lorentzian peak shapes are utilized for the deconvolution of the peaks and the full-width at half maximum (FWHM) of each line shape is restricted below $1.5 \mathrm{eV}$.

\section{Results and discussion}

\subsection{Characterization of the plasma jet}

\subsubsection{Optical emission spectroscopy}

The chemical species present in the plasma can be identified by optical emission spectroscopy (OES). The spectra were acquired by setting an exposition time of $5 \mathrm{~s}$ to increase the peak intensities present in the wavelength range between 310 and $660 \mathrm{~nm}$. Figure 3 (A) shows the emission spectrum of the argon plasma jet generated in the atmosphere, so without any liquid surrounding the plasma jet afterglow. In this case, very intensive emission lines can be found in the spectral region between 680 and $900 \mathrm{~nm}$, which can be assigned to different excited states of $\mathrm{Ar}^{28}$. The discharge also produces some UVB radiation, which belongs to transitions of the $\mathrm{OH}$ 
band at 288 and $308 \mathrm{~nm}$. Apart from the previously mentioned species, spectral lines from $\mathrm{N}_{2}(310-$ $430 \mathrm{~nm}$ ), atomic oxygen (297, 777 and $842 \mathrm{~nm}), \mathrm{NO}$ and $\mathrm{NO}_{2}$ species can also be identified (490 and $502 \mathrm{~nm}$ respectively) ${ }^{29}$. The identified $\mathrm{OH}$ and $\mathrm{O}$ species are the result of dissociation of oxygen and water in the air surrounding the plasma jet afterglow, while the excited $\mathrm{N}_{2}, \mathrm{NO}$ and $\mathrm{NO}_{2}$ species are most likely generated from direct excitation of nitrogen molecules present due to back diffusion of ambient air in the plasma region ${ }^{30}$.
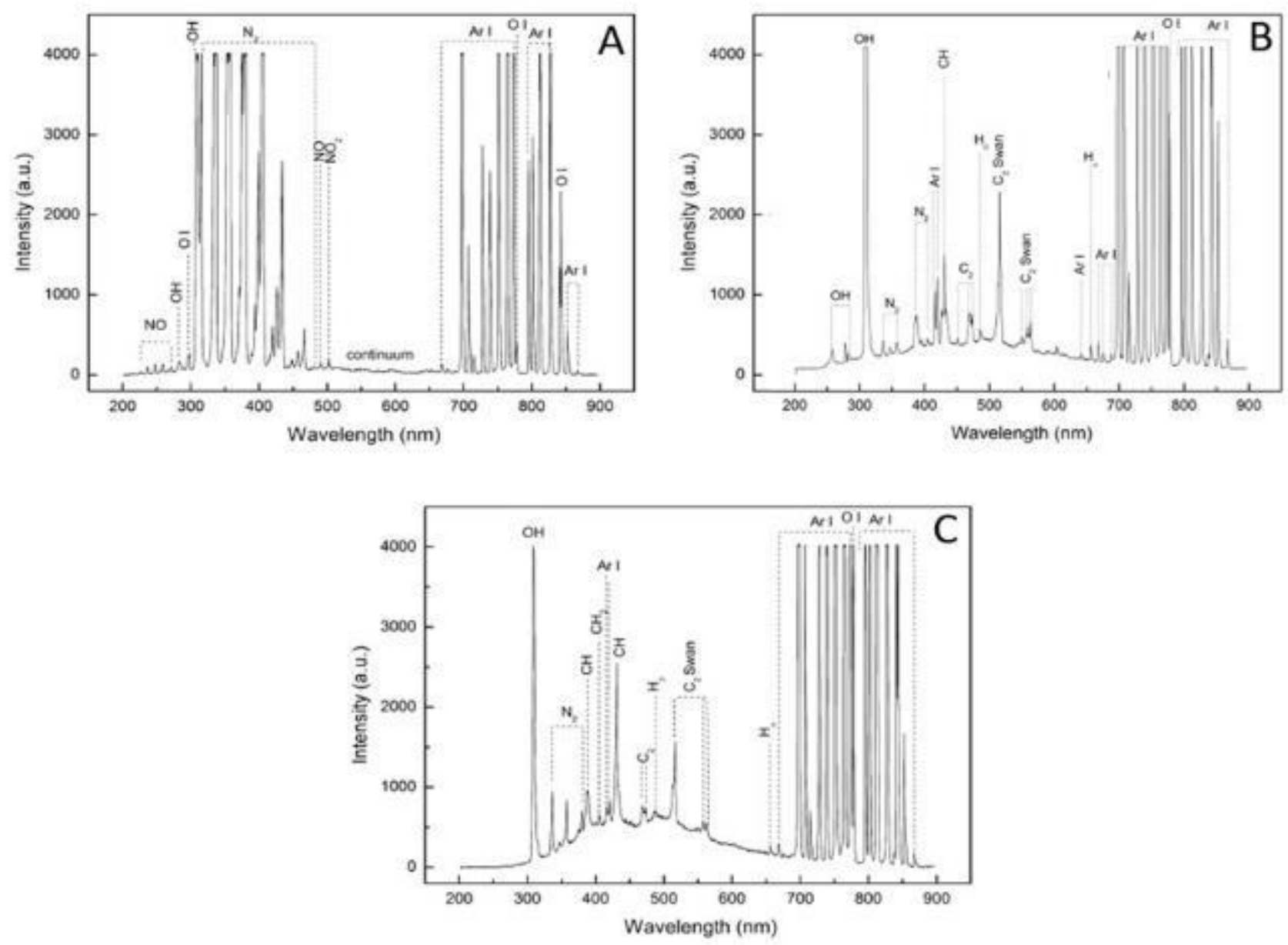

Figure 3. OES spectrum of the APPJ generated in the atmosphere without any liquid surrounding the plasma afterglow (A); OES spectrum of the APPJ during the treatment of only solvents (B) and OES spectrum of the APPJ during the polymeric solution treatment $(\mathrm{C})$. 
Figure 3 (B) presents the OES spectrum acquired during the plasma treatment of only the solvent mixture chloroform and DMF. In this spectrum, strong emission lines of Ar are still present similar to the spectrum of the plasma jet generated in the atmosphere. Emission lines of $\mathrm{N}_{2}$ are also visible, but with much lower intensities while $\mathrm{NO}$ and $\mathrm{NO}_{2}$ emission lines are no longer present in the spectrum. This is due to the fact that the plasma jet is no longer in direct contact with the surrounding air. The nitrogen emission lines can therefore only be the result of the degradation of DMF or from external air which may still be present in the solvents during the treatment process. In addition, emission lines of atomic oxygen and $\mathrm{OH}$ radicals can also be observed in Figure 3 (B) which can be attributed to the degradation of DMF or to the dissociation of oxygen and water present in the solvents. It is however also important to mention that absorption of the light will occur by the solvent mixture in the wavelength region below $300 \mathrm{~nm}$. As a result, it could be possible that additional OES peaks are present in this wavelength region, but that they cannot be detected due to absorption by the solvent mixture. The wavelength region between 450 and 700 $\mathrm{nm}$ also reveals that strong interactions between the solvent molecules and the plasma afterglow occur as emissions of $\mathrm{CH}(431 \mathrm{~nm}), \mathrm{C}_{2}(450 \mathrm{~nm}), \mathrm{C}_{2}$ Swan $(515$ and $563 \mathrm{~nm})$ and hydrogen $\left(\mathrm{H}_{\alpha}\right.$ : $656 \mathrm{~nm}$ and $\mathrm{H}_{\beta}: 486 \mathrm{~nm}$ ) can be found in the OES spectrum. The presence of these excited species thus clearly suggests that degradation of the solvent molecules occurs as a result of plasma exposure. Finally, Figure 3 (C) represents the OES spectrum of the discharge while treating the examined polymer solution (5\% PCL in $\left.\mathrm{CHCl}_{3}+\mathrm{DMF}\right)$. This spectrum is almost similar to the OES spectrum obtained during the treatment of the solvent mixture, except for two important changes: (1) no emission peaks can be observed below $309 \mathrm{~nm}$, which is probably due to the fact that light is scattered inside the polymer solution which presents a lower degree of optical transparency compared to the solvent mixture and/or the fact that PCL besides the used solvents 
also absorbs light below $300 \mathrm{~nm}$. As a result, OES peaks may be present below $300 \mathrm{~nm}$, but may be undetectable due to a pronounced absorption by the polymer solution; (2) an extra emission peak attributed to $\mathrm{CH}_{2}$ can be observed at $405 \mathrm{~nm}$. As $\mathrm{H}, \mathrm{CH}$, and $\mathrm{C}_{2}$ lines were already present in the OES spectrum of the plasma jet surrounded by the solvents alone, it can thus be suggested that these peaks are most likely the result of degradation of solvent molecules. The presence of excited $\mathrm{CH}_{2}$ in the emission spectrum could be attributed to degradation of the PCL polymer chains, however, according to the SEC results which will be reported in paragraph 3.2.2, polymer chain degradation does not occur thereby excluding the possibility that the $\mathrm{CH}_{2}$ peaks derive from polymer backbone degradation. The presence of excited $\mathrm{CH}_{2}$ in the $\mathrm{OES}$ spectrum of the polymer solution may be the result of the enhanced viscosity of the polymer solution upon plasma exposure, an effect which does not occur when only the solvents are exposed to the plasma. As a result of the enhanced viscosity, solvent molecules are most likely longer exposed to the plasma species due to their limited diffusion capacity, which can result in more extensive fragmentation of the solvent molecules and thus the presence of additional excited $\mathrm{CH}_{2}$.

\subsection{Characterization of the PCL polymer solutions}

\subsubsection{Physical characterization of the PCL polymer solutions}

As the physical properties of the polymer solution, such as conductivity, viscosity and surface tension play a crucial role in the electrospinning process, they are very important parameters to analyze. Table 1 summarizes the above mentioned properties for PCL solutions before and after plasma treatment with different exposure times $\left(\mathrm{T}_{\text {plasma }}\right)$. In addition, the $\mathrm{pH}$ value and the volume of the plasma-modified PCL solutions before and immediately after plasma modification were also measured and these results are shown in Table 1. Despite the use of a specific probe for non- 
aqueous solutions, it should also be emphasized that the $\mathrm{pH}$ values, reported in Table 1, represent a relative trend rather than a consistent accurate number ${ }^{31}$.

\begin{tabular}{|c|c|c|c|c|c|c|}
\hline $\begin{array}{c}\mathrm{T}_{\text {plasma }} \\
(\mathrm{min})\end{array}$ & Conductivity $(\mu \mathrm{S} / \mathrm{cm})$ & $\begin{array}{c}\text { Viscosity } \\
(\mathrm{cP})\end{array}$ & $\begin{array}{c}\text { Surface tension } \\
(\mathrm{mN} / \mathrm{m})\end{array}$ & $\begin{array}{c}\mathrm{V}_{\text {in }} \\
(\mathrm{ml})\end{array}$ & $\begin{array}{c}\mathrm{V}_{\text {out }} \\
(\mathrm{ml})\end{array}$ & $\mathrm{pH}$ \\
\hline 0 & $0.22 \pm 0.05$ & $85 \pm 5$ & $29.5 \pm 0.5$ & 10 & 10 & 4.6 \\
\hline 1 & $1.05 \pm 0.05$ & $179 \pm 3$ & $29.7 \pm 0.3$ & 10 & 9 & 1.3 \\
\hline 2 & $2.10 \pm 0.10$ & $204 \pm 5$ & $30.2 \pm 0.5$ & 10 & 8.5 & 0.7 \\
\hline 3 & $3.40 \pm 0.10$ & $286 \pm 5$ & $30.2 \pm 0.5$ & 10 & 7.5 & $<0.1$ \\
\hline 4 & $5.08 \pm 0.05$ & $320 \pm 4$ & $33.6 \pm 0.2$ & 10 & 6 & $<0.1$ \\
\hline 5 & $6.50 \pm 0.15$ & $354 \pm 4$ & $33.8 \pm 0.2$ & 10 & 5.5 & $<0.1$ \\
\hline
\end{tabular}

Table 1. Physical properties of PCL solutions before and after plasma modification.

Based on Table 1, one might conclude that plasma modification results in a strong increase in conductivity and viscosity, a minor increase in surface tension and a major decrease in $\mathrm{pH}$ of the PCL polymer solutions.

Nevertheless, before drawing such conclusions, it is very important to take into account the solvent evaporation during the treatment as this evaporation can also strongly affect the solution physical parameters. As shown in Table 1, the solution volume strongly decreases with increasing plasma treatment time. Since the observed solvent evaporation due to plasma modification strongly influences the polymer concentration in the solution and thus the final solution properties, it is very important to compare PCL solutions having similar polymer concentrations before and after plasma treatment. In this way, the effects of only the plasma treatment itself on the PCL solution properties can be observed. To enable such a comparison, $10 \mathrm{ml}$ of a $5 \% \mathrm{w} / \mathrm{v}$ PCL solution was only exposed to the flowing argon gas $(0.9 \mathrm{slm})$ for durations varying between 2 and 17 minutes (see Table 2) until the same volume as after plasma modification was reached. For these argon- 
streamed polymer solutions, the solution properties have also been determined and the results are shown in Table 2, together with the previously obtained results for the plasma-treated solutions to enable an easy comparison. Based on the changing solution volumes, the polymer concentration $\left(\mathrm{C}_{\text {polym }}\right)$ for each PCL solution has also been calculated and the results are also presented in Table 2.

These results suggest that the argon gas flow is causing solvent evaporation, but this evaporation becomes more enhanced when the plasma is also switched on. This enhanced solvent evaporation during plasma treatment cannot be attributed to heating of the polymer solution by the plasma, since the plasma treatment decreases the solution temperature with $1{ }^{\circ} \mathrm{C}$ for all investigated treatment durations. The enhanced solvent evaporation might however be the result of more intense bubble formation and nucleation in the solutions due to the plasma exposure leading to larger liquid-gas interfaces and thus a more pronounced evaporation.

\begin{tabular}{|c|c|c|c|c|c|c|c|c|c|c|c|}
\hline \multirow{2}{*}{$\begin{array}{c}V \\
(m l)\end{array}$} & \multirow{2}{*}{$\begin{array}{l}C_{\text {polym }} \\
(w / v \%)\end{array}$} & \multirow{2}{*}{$\begin{array}{l}T_{\text {Argon }} \\
\text { (min) }\end{array}$} & \multirow{2}{*}{$\begin{array}{c}T_{\text {plasma }} \\
\text { (min) }\end{array}$} & \multicolumn{4}{|c|}{ Argon-streamed solutions } & \multicolumn{4}{|c|}{ Plasma-modified solutions } \\
\hline & & & & $\begin{array}{c}\text { Conductivity } \\
(\mu \mathrm{S} / \mathrm{cm})\end{array}$ & $\begin{array}{c}\text { Viscosity } \\
\text { (cP) }\end{array}$ & $\begin{array}{c}\text { Surface } \\
\text { tension } \\
(\mathrm{mN} / \mathrm{m})\end{array}$ & $p H$ & $\begin{array}{c}\text { Conductivity } \\
(\mu \mathrm{S} / \mathrm{cm})\end{array}$ & $\begin{array}{c}\text { Viscosity } \\
\text { (cP) }\end{array}$ & $\begin{array}{l}\text { Surface } \\
\text { tension } \\
(\mathrm{mN} / \mathrm{m})\end{array}$ & $p H$ \\
\hline 10 & 5.0 & 0 & 0 & $0.22 \pm 0.05$ & $85 \pm 5$ & $29.5 \pm 0.5$ & 4.6 & $0.22 \pm 0.05$ & $85 \pm 5$ & $29.5 \pm 0.5$ & 4.6 \\
\hline 9 & 5.6 & 2 & 1 & $0.30 \pm 0.05$ & $105 \pm 5$ & $29.6 \pm 0.5$ & 4.0 & $1.05 \pm 0.05$ & $179 \pm 3$ & $29.7 \pm 0.3$ & 1.3 \\
\hline 8.5 & 5.9 & 4 & 2 & $0.38 \pm 0.04$ & $110 \pm 5$ & $30.0 \pm 0.5$ & 4.4 & $2.10 \pm 0.10$ & $204 \pm 5$ & $30.2 \pm 0.5$ & 0.7 \\
\hline 7 & 7.1 & 8 & 3 & $0.78 \pm 0.03$ & $150 \pm 5$ & $30.3 \pm 0.5$ & 4.5 & $3.40 \pm 0.10$ & $286 \pm 5$ & $30.2 \pm 0.5$ & $<0.1$ \\
\hline 6 & 8.3 & 15 & 4 & $1.25 \pm 0.05$ & $229 \pm 5$ & $29.8 \pm 0.5$ & 4.8 & $5.08 \pm 0.05$ & $320 \pm 4$ & $33.6 \pm 0.2$ & $<0.1$ \\
\hline 5.5 & 9.1 & 17 & 5 & $1.80 \pm 0.10$ & $336 \pm 5$ & $30.0 \pm 0.5$ & 3.9 & $6.50 \pm 0.15$ & $354 \pm 4$ & $33.8 \pm 0.2$ & $<0.1$ \\
\hline
\end{tabular}

Table 2. Solution physical parameters and polymer concentration for argon-streamed and plasmamodified polymer solutions.

Table 2 clearly shows that the plasma treatment itself significantly increases the solution conductivity. At the same time, also solution viscosity is increased while surface tension only slightly increases at long plasma exposure times. A possible hypothesis for these observed changes is that plasma modification induces degradation of the solvent molecules leading to the creation of 
chemical species characterized by a high conductivity, such as for example hydrogen chloride $(\mathrm{HCl})$ and/or nitric acid $\left(\mathrm{HNO}_{3}\right)$ and/or peroxynitrite $\left(\mathrm{ONOO}^{-}\right)^{32}$. Generation of these species could at the same time also explain the low $\mathrm{pH}$ values obtained after plasma modification, as $\mathrm{HCl}$ and $\mathrm{HNO}_{3}$ are known to be strong acids. In addition, these species are also highly polar which can result in a higher PCL solubility and thus expansion of the PCL coils, which could in turn explain the observed enhanced viscosity after plasma modification. This hypothesis is also in agreement with the previously obtained OES results suggesting that degradation of solvent molecules occurs during plasma modification. Further chemical experiments need to be carried out to verify these assumptions.

\subsubsection{Determination of the PCL molecular weight distribution by SEC}

Based on the above mentioned changes in physical parameters, one can expect that plasma modification can induce significant chemical and/or physical changes to the PCL polymer chains as well as to the solvent molecules. However, within this context, it is important to avoid degradation of the PCL polymer chains by plasma exposure as this can lead to unsatisfactory mechanical properties of the resulting nanofibers ${ }^{33}$. Therefore, it is crucial to investigate if the plasma modification step is not affecting the PCL molecular weight, which is examined in this work making use of SEC. The chromatograms of an untreated and a plasma-modified PCL solution (exposure time of 3 minutes) are presented in Figure 4 and show how much polymeric material exits the column at a given time, with the large, high molecular weight polymer chains eluting first, followed by successively smaller (and thus lower molecular weight) chains emerging later ${ }^{34}$. Figure 4 clearly shows that the plasma treatment does not significantly change the molecular weight distribution of the PCL polymer chains as the chromatographs of untreated and plasmamodified solutions almost completely overlap. In addition, only a very small difference in number 
averaged molecular weight $\left(\mathrm{M}_{\mathrm{n}}\right)$ as well as polydispersity $(\mathrm{PD})$, which may be even considered negligible, can be observed as can be seen in Figure 4. Based on this result, it can be concluded that the plasma modification is not significantly degrading the PCL polymer chains and will therefore not affect the mechanical properties of the resultant PCL nanofibers.

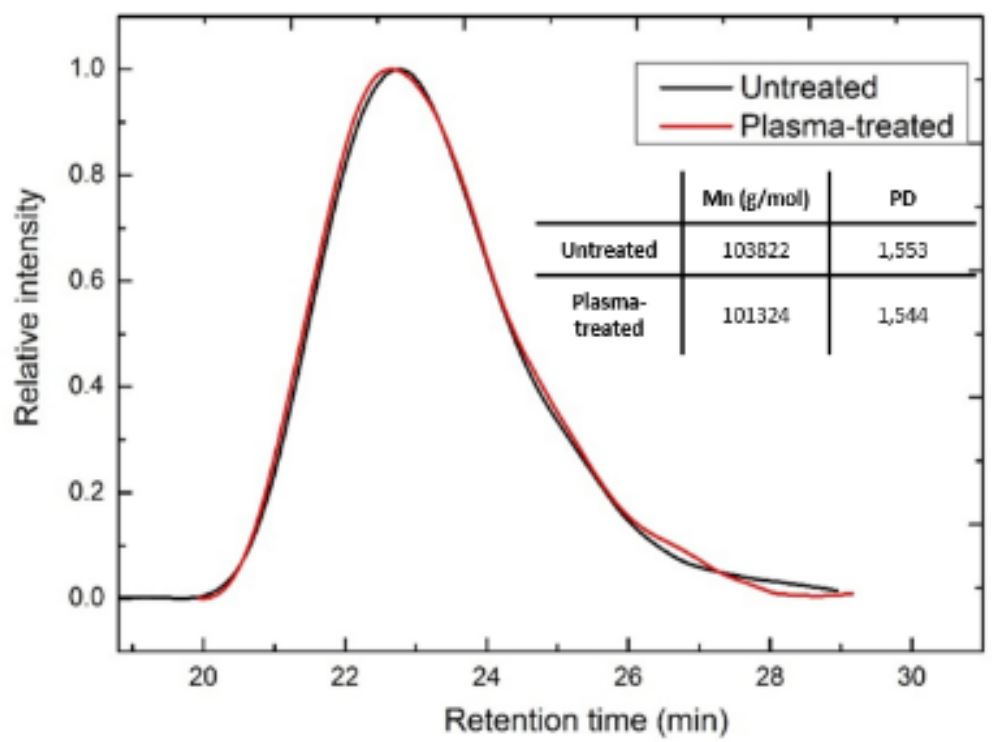

Figure 4. Size exclusion chromatographs of an untreated (no plasma treatment no argon streaming) and plasma-modified PCL solution (plasma exposure time $=3$ minutes) including number averaged molecular weight $\left(\mathrm{M}_{\mathrm{n}}\right)$ and polydispersity $(\mathrm{PD})$.

\subsection{Characterization of the electrospun PCL nanofibers}

\subsubsection{Morphology of the electrospun materials}

The plasma treatment effect on the electrospinnability of PCL will be examined in this section by SEM observation of the generated nanofibers. In particular, the morphology as well as the average fiber diameter of electrospun mats generated from untreated as well as plasma-modified solutions will be compared. The left column of Figures 5 and 6 shows the SEM image of the nanofibers obtained from an untreated PCL solution (no argon streaming) as well as the SEM images of electrospun mats obtained from untreated solutions which have been exposed to an argon flow for a well-defined time to obtain untreated PCL solutions having the same polymer 
concentration as after plasma modification which can thus act as control samples. In the right column of Figures 5 and 6 SEM images of electrospun mats obtained from plasma-treated solutions with different plasma exposure times can be observed. By doing so, an easy comparison can be made between PCL solutions with a similar polymer concentration: the control sample on the left and the plasma-modified sample on the right.

Figures 5 and 6 clearly reveal that electrospinning of the untreated PCL solution $(5 \mathrm{w} / \mathrm{v} \%)$ results in the generation of non-uniform fibers containing a large number of beads (with an estimation of 2000 beads per $\mathrm{mm}^{2}$ ). However, as the polymer concentration increases, the fibers tend to become more and more uniform with less beads. Finally, at the highest polymer concentration $(9.1 \mathrm{w} / \mathrm{v} \%)$, almost beadless (approximately 300 beads per $\mathrm{mm}^{2}$ ) electrospun nanofibers can be obtained, possessing a fiber diameter of $0.494 \pm 0.243 \mu \mathrm{m}$ (see Table 3). Taking into account the large standard deviation on this average fiber diameter, one can also conclude that even at the highest polymer concentration the PCL nanofibers fibers are not uniform in diameter.

This behavior can be explained as follows: if the concentration of the PCL solution is too low, the applied electric field and surface tension causes the entangled polymer chains to break into fragments before reaching the collector resulting in the formation of beaded nanofibers. When the concentration of the PCL solution is increased, an increase in viscosity appears (as shown in Table 2), which leads to an increase in elongation of the jet before it breaks into smaller droplets ${ }^{35}$ thereby resulting in the generation of almost beadless electrospun nanofibers. Unfortunately, the generated nanofibers are at the same time not uniform in fiber diameter. 

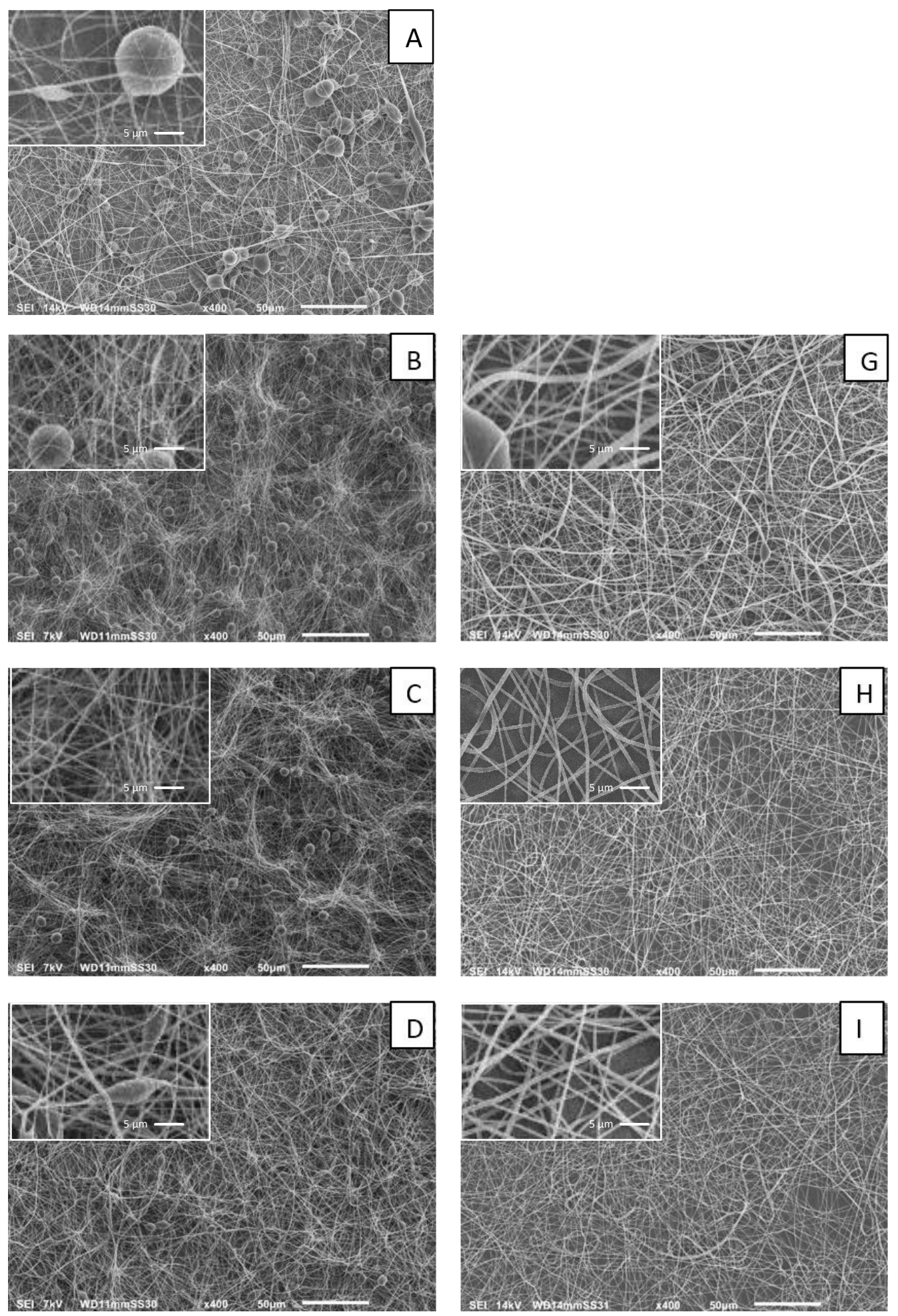

Figure 5. SEM images of nanofibers obtained from an untreated control solution with a PCL concentration equal to 5\% (A), argon-streamed control solutions (left column) and plasmamodified solutions (right column) at different PCL polymer concentrations: $5.6 \mathrm{w} / \mathrm{v} \%(\mathrm{~B}, \mathrm{G}), 5.9$ $\mathrm{w} / \mathrm{v} \%(\mathrm{C}, \mathrm{H})$ and $7.1 \mathrm{w} / \mathrm{v} \%(\mathrm{D}, \mathrm{I})$. 

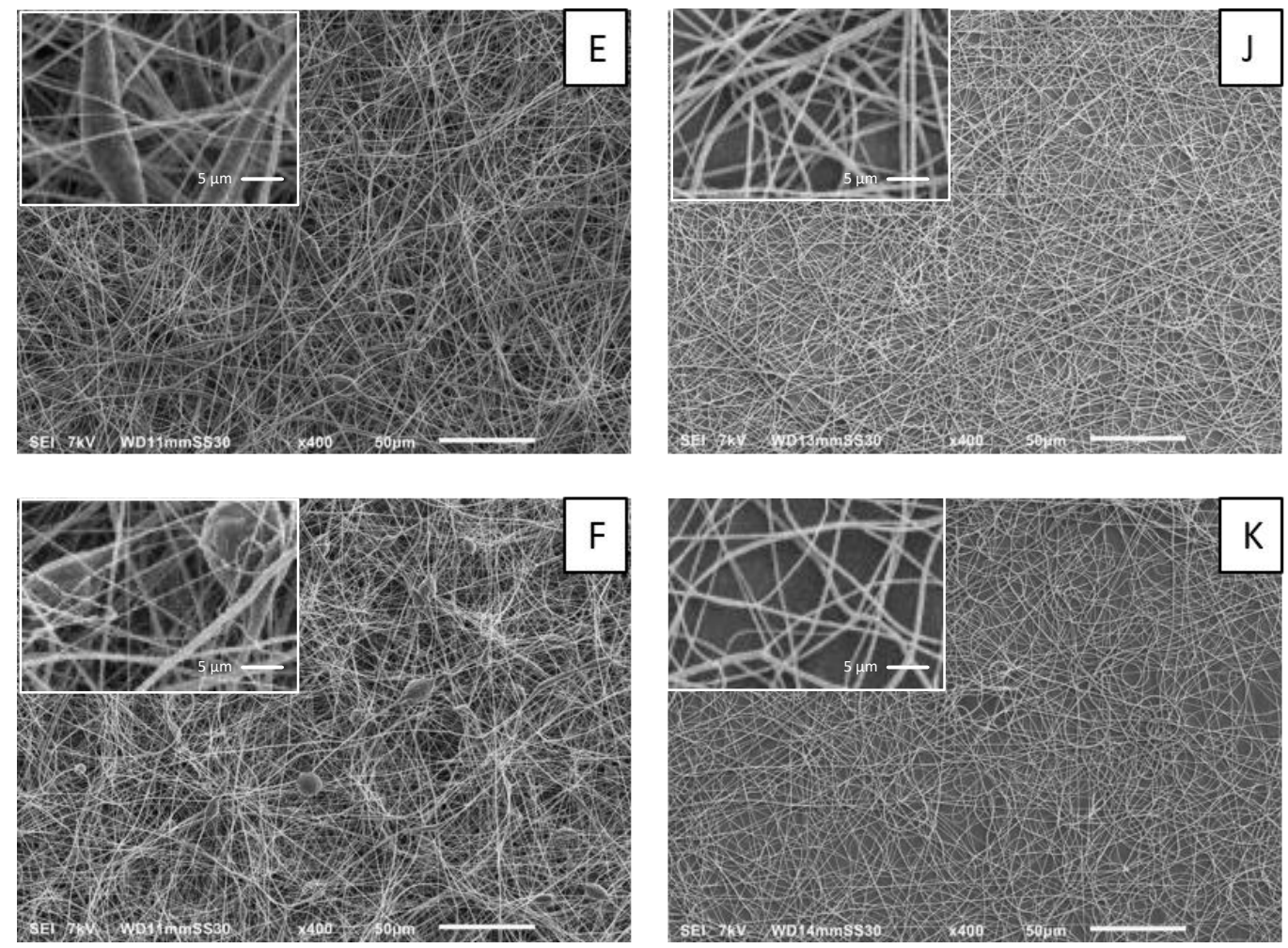

Figure 6. SEM images of nanofibers obtained from argon-streamed control solutions (left column) and plasma-modified solutions (right column) at high PCL polymer concentrations of $8.3 \mathrm{w} / \mathrm{v} \%$ $(\mathrm{E}, \mathrm{J})$ and $9.1 \mathrm{w} / \mathrm{v} \%(\mathrm{~F}, \mathrm{~K})$.

Figures 5 and 6 also show that plasma treatment causes a significant decrease in bead numbers combined with a significant improvement in the uniformity of the PCL nanofibers. Although a plasma treatment time of 1 minute was not yet sufficient to completely prevent the formation of beads along the fibers, higher plasma exposure times result in the generation of uniform beadless nanofibers. Increasing the plasma treatment duration from 2 minutes up to 5 minutes does not result in a further improvement in fiber morphology. Even though the average fiber diameter remains constant within standard deviation, there seems to be a marginal decrease in fiber diameter to $450 \mathrm{~nm}$ with increasing plasma exposure time and the uniformity of the fibers also improves as 
can be seen in Table 3 from the decreasing standard deviations on the average fiber diameter with increasing plasma exposure time.

When comparing the control argon-streamed and plasma-modified samples at the highest polymer concentration $(9.1 \mathrm{w} / \mathrm{v} \%)$, beadless fibers can be found in both samples, nevertheless, the fiber diameter in case of the plasma-modified solutions is slightly lower and much more uniform, as can be observed in Figure $6(\mathrm{~F}, \mathrm{~K})$ and Table 3. This observation can only been explained by the higher solution conductivity after plasma modification, as the plasma-modified samples have a higher viscosity which is known to result in thicker fibers ${ }^{36}$. As a result of the higher solution conductivity, more stretching of the solution jet occurs resulting in the generation of thinner fibers as was already previously observed by Angamanna et al. ${ }^{37}$.

\begin{tabular}{|c|c|c|c|}
\hline \multirow{2}{*}{$\begin{array}{c}C_{p o l y m} \\
(w / v \%)\end{array}$} & \multirow{2}{*}{$\begin{array}{l}T_{\text {plasma }} \\
\text { (min) }\end{array}$} & Argon-streamed solutions & Plasma-modified solutions \\
\hline & & Average fiber diameter $(\mu \mathrm{m})$ & Average fiber diameter $(\mu \mathrm{m})$ \\
\hline 5.0 & 0 & / & / \\
\hline 5.6 & 1 & / & $0.582 \pm 0.269$ \\
\hline 5.9 & 2 & I & $0.488 \pm 0.126$ \\
\hline 7.1 & 3 & / & $0.467 \pm 0.122$ \\
\hline 8.3 & 4 & $0.577 \pm 0.376$ & $0.461 \pm 0.123$ \\
\hline 9.1 & 5 & $0.494 \pm 0.243$ & $0.450 \pm 0.090$ \\
\hline
\end{tabular}

Table 3. Average fiber diameter of electrospun mats generated from argon-streamed and plasmamodified PCL solutions (fiber diameter was not determined in case a lot of beads were present in the electrospun mats).

\subsubsection{Imaging of the electrospinning jet path}

To further investigate why plasma modification improves the electrospinnability of the PCL solution, imaging of the electrospinning process has also been carried out to visualize the electrospinning jet path. Upon initiation of electrospinning, electrospinning jet paths show a straight segment where the polymer and solvent molecules move along a certain axis followed by a bending instability region ${ }^{38}$ where the jet begins to oscillate around this axis creating a three- 
dimensional coil following a whipping and circling path. This typical shape of the electrospinning jet path can also be observed during the electrospinning process of untreated and plasma-modified PCL solutions as shown in superimposed images of multiple electrospinning jet paths presented in Figure 7. These figures reveal that the electrospinning jet path is different for the plasma-modified solution compared to the untreated one. In particular, in case of the plasma-modified solution, a reduction in the straight segment occurs from $13.3 \mathrm{~mm}$ down to $7.2 \mathrm{~mm}$. In addition, a more extended bending instability region can also be observed for the plasma-modified solution as evidenced from the diameter increase of this region from $3.50 \mathrm{~mm}$ for the untreated solution to $4.50 \mathrm{~mm}$ for the plasma-modified sample. These macroscopic changes in electrospinning paths are most likely the result of the strongly increased conductivity of the PCL solution after plasma modification. The higher concentration of ions in the plasma-treated solution increases the surface charges which reduce the length of the straight segment in favor of the jet spiral path. Consequently, the plasma-modified solution contributes to larger bending instabilities and as a result a reduction in stable jet length ${ }^{39}$. Because of the greater bending instabilities, more stretching of the solution jet occurs during electrospinning resulting in the generation of bead-free fibers, as was observed when examining the morphology of the fibers ${ }^{37}$. In addition, when the solution conductivity is further increased with increasing plasma exposure time, more bending instabilities also appear resulting in the generation of fibers with smaller fiber diameters as previously observed in this work. 

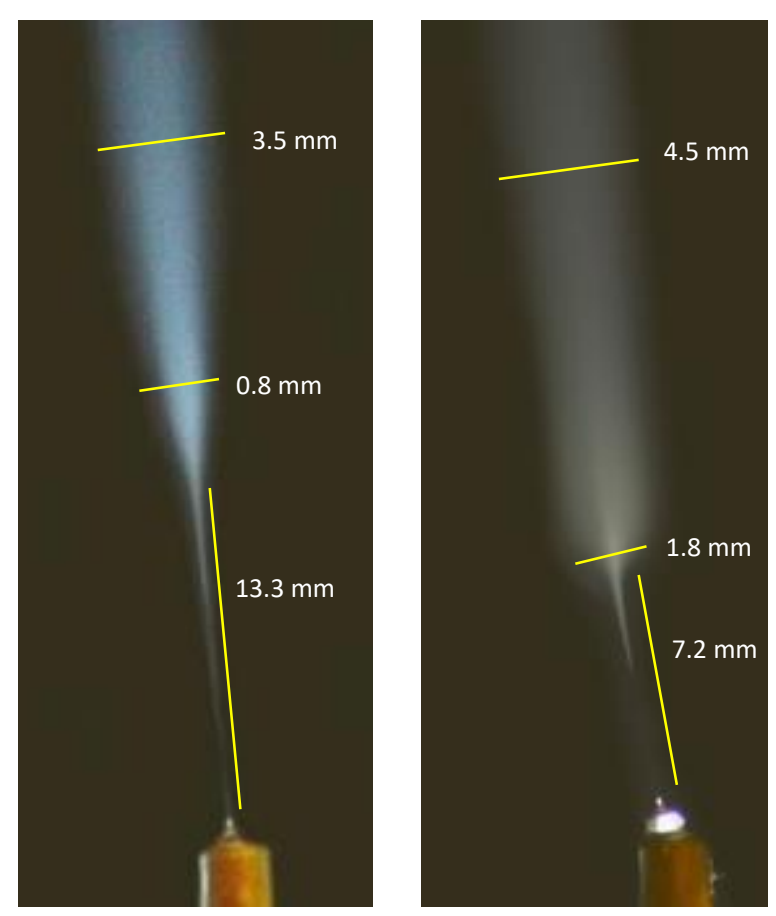

Figure 7. Superimposed images of multiple electrospinning jet paths of an untreated (no plasma, no argon streaming) PCL solution (left) and a plasma-modified PCL solution (right, plasma exposure time of $3 \mathrm{~min}$ ).

\subsubsection{Chemical characterization of the nanofibers by XPS}

To investigate whether the plasma modification of the PCL polymer solutions is not affecting the chemical surface composition of the nanofibers, XPS analysis is also performed on PCL nanofibers generated from untreated and plasma-modified solutions (plasma treatment time of 3 minutes). In a first step, XPS survey scans were taken to obtain the elemental composition of the nanofibers. PCL nanofibers created from unmodified PCL solutions were found to contain $77.0 \pm$ $0.5 \%$ of carbon and $23.0 \pm 0.5 \%$ of oxygen, which is close to the theoretical values expected for PCL $(75 \% \mathrm{C}, 25 \% \mathrm{O})$. A similar elemental composition was also observed for PCL nanofibers generated from a plasma-modified solution $(76.3 \pm 0.3 \% \mathrm{C}$ and $23.7 \pm 0.3 \% \mathrm{O})$ suggesting that preelectrospinning plasma exposure does not affect the surface chemical composition of the electrospun PCL nanofibers. 
High resolution peak fitting of the C1s peaks has also been performed in this work to check if any changes in surface chemical groups occur as a result of the plasma modification step. In Figure 8, these fitted C1s peaks are shown for nanofibers generated from the untreated PCL solution (left) and from the plasma-modified PCL solution (right). As can be seen, these C1s spectra are fitted with 3 components for both samples: a peak at $285.0 \mathrm{eV}$, which can be attributed to $\mathrm{C}-\mathrm{C} / \mathrm{C}-\mathrm{H}$ bonds, a peak at $286.4 \mathrm{eV}$ which can be correlated with C-O bonds and a peak at $289.1 \mathrm{eV}$ which is the result of ester $(\mathrm{O}-\mathrm{C}=\mathrm{O})$ bonds. As can be seen in Figure 8, there are no significant changes detectable between the fitted $\mathrm{C} 1 \mathrm{~s}$ spectrum of the nanofibers obtained from the untreated solution and the one generated from the plasma-modified solution. Based on the fitted C1s peaks, the concentration of the different chemical bonds on the PCL nanofibers can also be determined and the results are as follows: the pristine nanofibers contain $46.2 \pm 0.8 \%$ of C-C/C-H bonds, $40.4 \pm$ $0.8 \%$ of $\mathrm{C}-\mathrm{O}$ bonds and $13.5 \pm 0.1 \%$ of $\mathrm{O}-\mathrm{C}=\mathrm{O}$ bonds while the nanofibers from plasma-modified solutions contain $44.3 \pm 1.1 \%$ of C-C/C-H bonds, $42.2 \pm 1.3 \%$ of C-O bonds and $13.4 \pm 0.2 \%$ of $\mathrm{O}-\mathrm{C}=\mathrm{O}$ groups. These XPS results thus clearly show that plasma modification of a preelectrospinning PCL solution does not induce any surface chemical changes on the PCL polymer chains and does not change its MW as previously determined by SEC, which is very beneficial as the preservation of the chemical composition of the original polymer is crucial in most 
applications. As a result, it can be concluded that the APPJ mainly degrades the small solvent molecules instead of modifying the large PCL macromolecules.
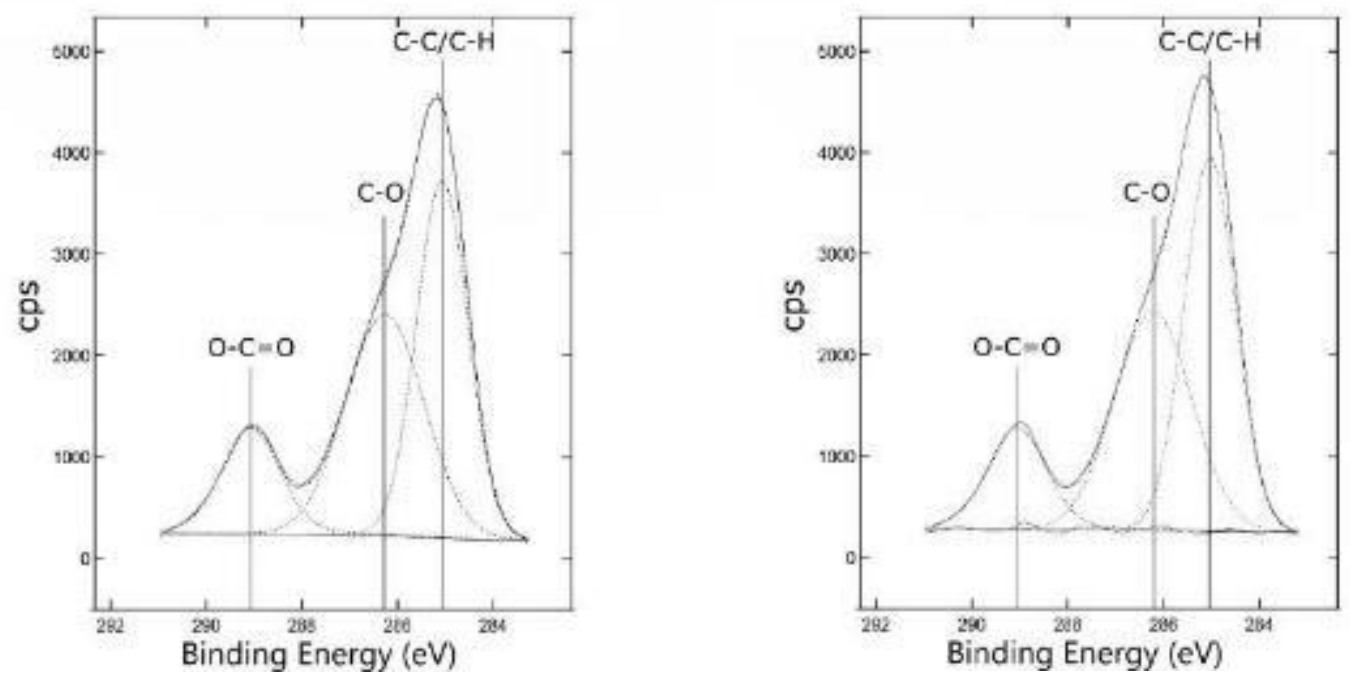

Figure 8. High resolution C1s spectra of PCL nanofibers generated from an unmodified (no plasma, no argon streaming) (left) and a 3 min plasma-treated polymer solution (right).

\section{Conclusion}

In this work, an atmospheric pressure plasma jet has been successfully applied to improve the electrospinnability of PCL polymer solutions. Plasma treatment exposure times of 2 to 5 minutes enabled the generation of beadless, uniform PCL nanofibers with an average diameter of approximately $450 \mathrm{~nm}$. This enhanced electrospinnability was found to be the result of the highly increased conductivity of the plasma-modified polymer solutions, possibly in combination with the observed viscosity increase. Imaging of the electrospinning polymer jet clearly revealed that larger bending instabilities occur for the plasma-modified solutions as a result of their high conductivity. Consequently, more stretching of the jet occurs during electrospinning leading to the generation of bead-free fibers. 
Experiments conducted in this work also reveal that plasma treatment not only increases the solution conductivity, but also results in highly increased viscosities and $\mathrm{pH}$ values. A hypothesis for these observed macroscopic changes is that plasma modification induces chemical changes in the polymer solutions leading to the creation of new chemical species such as for example $\mathrm{HCl}$ and $\mathrm{HNO}_{3}$. These species are not only characterized by a high conductivity and a low $\mathrm{pH}$ value, but are also highly polar, which could be a reason for the observed enhanced viscosity as polar solvents are known to positively affect the solubility of PCL polymer chains. Optical emission spectroscopy results also reveal that degradation of solvent molecules occurs during plasma jet treatment since peaks attributed to $\mathrm{H}, \mathrm{CH}, \mathrm{CH}_{2}$ and $\mathrm{C}_{2}$ lines can be observed in the emission spectrum. Based on the OES results, it was also found that the plasma-induced degradation of these solvent molecules is more pronounced when working with polymer solutions instead of solvent mixtures as a result of the highly increased viscosity of polymer solutions upon plasma exposure. It was also found in this work that plasma modification of PCL polymer solutions does not affect the molecular weight and the surface chemical composition of the final PCL nanofibers thereby suggesting that the generated non-thermal plasma mainly degrades the small solvent molecules instead of the large PCL macromolecules, which is quite logical taking into account the small size and the high concentration of the solvent molecules. This conclusion is very beneficial taking into account the fact that the original polymer should be preserved as much as possible when applying the nanofibrous mats for biomedical purposes.

\section{Corresponding Author}

*E-mail: $\underline{\text { Silvia.Grande@UGent.be }}$

\section{ORCID}

Silvia Grande 0000-0001-6912-4480 


\section{Author Contributions}

The manuscript was written through contributions of all authors. All authors have given approval to the final version of the manuscript.

\section{Funding Sources}

This research has received funding from the European Research Council (ERC) under the

European Union's Seventh Framework Program (FP2007-2013): ERC Grant Agreement number 335929 (PLASMATS) and ERC Grant Agreement number 279022 (PLASMAPOR).

\section{References}

(1) Frenot, A.; Chronakis, I. S. Polymer Nanofibers Assembled by Electrospinning. Curr. Opin. Colloid Interface Sci. 2003, 8 (1), 64-75.

(2) Liu, X.; Li, M.; Han, G.; Dong, J. The Catalysts Supported on Metallized Electrospun Polyacrylonitrile Fibrous Mats for Methanol Oxidation. Electrochim. Acta 2010, 55 (8), 2983-2990.

(3) Geltmeyer, J.; Vancoillie, G.; Steyaert, I.; Breyne, B.; Cousins, G.; Lava, K.; Hoogenboom, R.; De Buysser, K.; De Clerck, K. Dye Modification of Nanofibrous Silicon Oxide Membranes for Colorimetric $\mathrm{HCl}$ and NH3 sensing. Adv. Funct. Mater. 2016, 26 (33), 5987-5996.

(4) Steyaert, I.; Vancoillie, G.; Hoogenboom, R.; De Clerck, K. Dye Immobilization in Halochromic Nanofibers through Blend Electrospinning of a Dye-Containing Copolymer and Polyamide-6. Polym. Chem. 2015, 6 (14), 2685-2694.

(5) Choi, J. S.; Lee, S. J.; Christ, G. J.; Atala, A.; Yoo, J. J. The linfluence of Electrospun Aligned Poly (epsilon-caprolactone)/Collagen Nanofiber Meshes on the Formation of Self-Aligned Skeletal Muscle Myotubes. Biomaterials 2008, 29 (19), 2899-2906.

(6) Vitchuli, N.; Shi, Q.; Nowak, J.; McCord, M.; Bourham, M.; Zhang, X. Electrospun Ultrathin Nylon Fibers for Protective Applications. J. Appl. Polym. Sci. 2010, 116 (4), 2181-2187.

(7) Thavasi, V.; Singh, G.; Ramakrishna, S. Electrospun Nanofibers in Energy and Environmental Applications. Energy Environ. Sci. 2008, 1 (2), 205-221.

(8) Bhardwaj, N.; Kundu, S. C. Electrospinning: a Fascinating Fiber Fabrication Technique. Biotechnol. Adv. 2010, 28 (3), 325-347.

(9) Bosworth, L.; Downes, S. Electrospinning for Tissue Regeneration, Elsevier: 2011.

(10) Doshi, J.; Reneker, D. H. Electrospinning Process and Applications of Electrospun Fibers. J. Electrost. 1995, 35 (2-3), 151-160.

(11) Pham, Q. P.; Sharma, U.; Mikos, A. G. Electrospinning of Polymeric Nanofibers for Tissue Engineering Applications: a Review. Tissue Eng. 2006, 12 (5), 1197-1211.

(12) Hsu, C. M.; Shivkumar, S. N, N-Dimethylformamide Additions to the Solution for the Electrospinning of Poly ( $\varepsilon$-caprolactone) Nanofibers. Macromol. Mater. Eng. 2004, 289 (4), 334-340. 
(13) Tungprapa, S.; Puangparn, T.; Weerasombut, M.; Jangchud, I.; Fakum, P.; Semongkhol, S.; Meechaisue, C.; Supaphol, P. Electrospun Cellulose Acetate Fibers: Effect of Solvent System on Morphology and Fiber Diameter. Cellulose 2007, 14 (6), 563-575.

(14) Ryu, S.-Y.; Kwak, S.-Y. Role of Electrical Conductivity of Spinning Solution on Enhancement of Electrospinnability of Polyamide 6, 6 Nanofibers. J. Nanosci. Nanotechnol. 2013, 13 (6), 4193-4202.

(15) Qin, X. H.; Yang, E. L.; Li, N.; Wang, S. Y. Effect of Different Salts on Electrospinning of Polyacrylonitrile (PAN) Polymer Solution. J. Appl. Polym. Sci. 2007, 103 (6), 3865-3870.

(16) Stubbe, B.; Li, Y.; Vergaelen, M.; Van Vlierberghe, S.; Dubruel, P.; De Clerck, K.; Hoogenboom, R. Aqueous Electrospinning of Poly (2-ethyl-2-oxazoline): Mapping the Parameter Space. Eur. Polym. J. 2017, 88, 724-732.

(17) Colombo, V.; Fabiani, D.; Focarete, M. L.; Gherardi, M.; Gualandi, C.; Laurita, R.; Zaccaria, M. Atmospheric Pressure Non-Equilibrium Plasma Treatment to Improve the Electrospinnability of Poly (LLactic Acid) Polymeric Solution. Plasma Processes Polym. 2014, 11 (3), 247-255.

(18) Shi, Q.; Vitchuli, N.; Nowak, J.; Lin, Z.; Guo, B.; McCord, M.; Bourham, M.; Zhang, X. Atmospheric Plasma Treatment of Pre-Electrospinning Polymer Solution: A Feasible Method to Improve Electrospinnability. J. Polym. Sci., Part B: Polym. Phys. 2011, 49 (2), 115-122.

(19) De Geyter, N.; Sarani, A.; Jacobs, T.; Nikiforov, A. Y.; Desmet, T.; Dubruel, P. Surface Modification of Poly- $\varepsilon$-caprolactone with an Atmospheric Pressure Plasma Jet. Plasma Chem. Plasma Process. 2013, 33 (1), 165-175.

(20) Can-Herrera, L.; Ávila-Ortega, A.; de la Rosa-García, S.; Oliva, A.; Cauich-Rodríguez, J.; Cervantes-Uc, J. Surface modification of electrospun polycaprolactone microfibers by air plasma treatment: Effect of plasma power and treatment time. European Polymer Journal 2016, 84, 502-513.

(21) Cipitria, A.; Skelton, A.; Dargaville, T.; Dalton, P.; Hutmacher, D. Design, Fabrication and Characterization of PCL Electrospun Scaffolds-a Review. J. Mater. Chem. 2011, 21 (26), 9419-9453.

(22) Yoshimoto, H.; Shin, Y.; Terai, H.; Vacanti, J. A Biodegradable Nanofiber Scaffold by Electrospinning and its Potential for Bone Tissue Engineering. Biomaterials 2003, 24 (12), 2077-2082.

(23) Nottelet, B.; Pektok, E.; Mandracchia, D.; Tille, J. C.; Walpoth, B.; Gurny, R.; Moeller, M. Factorial Design Optimization and In Vivo Feasibility of Poly ( $\varepsilon$-caprolactone)-Micro-and Nanofiber-Based Small Diameter Vascular Grafts. J. Biomed. Mater. Res., Part A 2009, 89 (4), 865-875.

(24) Pişkin, E.; İ̧oğlu, İ. A.; Bölgen, N.; Vargel, İ.; Griffiths, S.; Çavuşoğlu, T.; Korkusuz, P.; Güzel, E.; Cartmell, S. In Vivo Performance of Simvastatin-Loaded Electrospun Spiral-Wound Polycaprolactone Scaffolds in Reconstruction of Cranial Bone Defects in the Rat Model. J. Biomed. Mater. Res., Part A 2009, 90 (4), 1137-1151.

(25) Wagner, H.-E.; Brandenburg, R.; Kozlov, K.; Sonnenfeld, A.; Michel, P.; Behnke, J. The Barrier Discharge: Basic Properties and Applications to Surface Treatment. Vacuum 2003, 71 (3), 417-436.

(26) Rame, E. The Interpretation of Dynamic Contact Angles Measured by the Wilhelmy Plate Method. J. Colloid Interface Sci. 1997, 185 (1), 245-251.

(27) Hiljanen-Vainio, M.; Karjalainen, T.; Seppälä, J. Biodegradable Lactone Copolymers. I.

Characterization and Mechanical Behavior of $\varepsilon$-caprolactone and Lactide Copolymers. J. Appl. Polym. Sci. 1996, 59 (8), 1281-1288.

(28) Sarani, A.; Nikiforov, A. Y.; De Geyter, N.; Morent, R.; Leys, C. Surface Modification of Polypropylene with an Atmospheric Pressure Plasma Jet Sustained in Argon and an Argon/Water Vapour Mixture. Appl. Surf. Sci. 2011, 257 (20), 8737-8741.

(29) Nikiforov, A. Y.; Sarani, A.; Leys, C. The Influence of Water Vapor Content on Electrical and Spectral Properties of an Atmospheric Pressure Plasma Jet. Plasma Sources Sci. Technol. 2011, 20 (1), 015014. (30) Sarani, A.; Nikiforov, A. Y.; Leys, C. Atmospheric Pressure Plasma Jet in Ar and Ar/H 2 O Mixtures: Optical Emission Spectroscopy and Temperature Measurements. Phys. Plasmas 2010, 17 (6), 063504. 
(31) Mussini, T.; Covington, A.; Longhi, P.; Rondinini, S. Criteria for Standardization of pH Measurements in Organic Solvents and Water+Organic Solvent Mixtures of Moderate to High Permittivities. Pure Appl. Chem. 1985, 57 (6), 865-876.

(32) Lukes, P.; Dolezalova, E.; Sisrova, I.; Clupek, M. Aqueous-Phase Chemistry and Bactericidal Effects from an Air Discharge Plasma in Contact with Water: Evidence for the Formation of Peroxynitrite through a Pseudo-Second-Order Post-Discharge Reaction of H2O2 and HNO2. Plasma Sources Sci. Technol. 2014, 23 (1), 015019.

(33) Hutmacher, D. W.; Schantz, T.; Zein, I.; Ng, K. W.; Teoh, S. H.; Tan, K. C. Mechanical Properties and Cell Cultural Response of Polycaprolactone Scaffolds Designed and Fabricated via Fused Deposition Modeling. J. Biomed. Mater. Res., Part A 2001, 55 (2), 203-216.

(34) Striegel, A.; Yau, W. W.; Kirkland, J. J.; Bly, D. D. Modern Size-Exclusion Liquid Chromatography: Practice of Gel Permeation and Gel Filtration Chromatography, John Wiley \& Sons: 2009.

(35) de Gans, B. J.; Xue, L.; Agarwal, U. S.; Schubert, U. S. Ink-Jet Printing of Linear and Star Polymers. Macromol. Rapid Commun. 2005, 26 (4), 310-314.

(36) Nezarati, R. M.; Eifert, M. B.; Cosgriff-Hernandez, E. Effects of Humidity and Solution Viscosity on Electrospun Fiber Morphology. Tissue Eng., Part C 2013, 19 (10), 810-819.

(37) Angammana, C. J.; Jayaram, S. H. Analysis of the Effects of Solution Conductivity on Electrospinning Process and Fiber Morphology. IEEE Trans. Ind. Appl. 2011, 47 (3), 1109-1117.

(38) Reneker, D. H.; Yarin, A. L. Electrospinning Jets and Polymer Nanofibers. Polymer 2008, 49 (10), 2387-2425.

(39) Sun, Z.; Deitzel, J. M.; Knopf, J.; Chen, X.; Gillespie, J. W. The Effect of Solvent Dielectric Properties on the Collection of Oriented Electrospun Fibers. J. Appl. Polym. Sci. 2012, 125 (4), 2585-2594.

\section{Table of Contents graphic/Graphical Abstract}

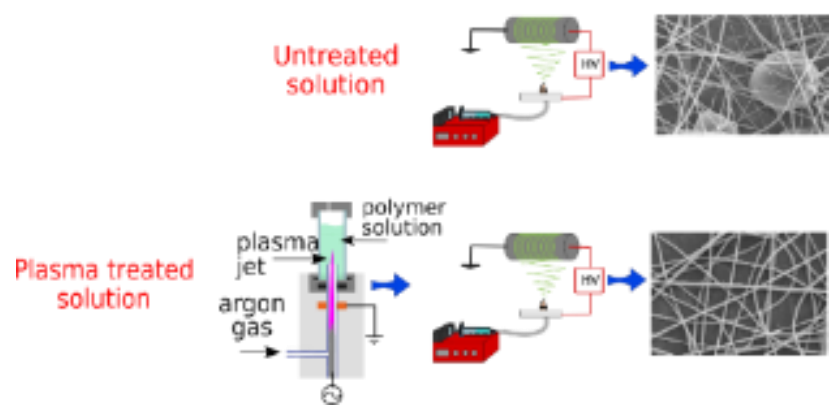


